\title{
Research on Values and Approaches to Setting up Volunteer Models
}

\author{
Fangbing Meng \\ Wuhan University of Technology, Wuhan 430070, China \\ whutmfb@126.com
}

Keywords: volunteer models; value; approach.

\begin{abstract}
Voluntary services play an important role in the following areas: social moral establishment, improvement of citizen qualities, formations of harmonious relations of all kinds during social transformation period. From the perspective of social cognition, this paper analyses the relation between social cognition degree of volunteer models and their conducts. It also studies the value and significance of setting volunteer models. It actively explores the modes and approaches to setting volunteer models so as to promote the efficient management of volunteer models and provide references and advice for the correct knowledge of volunteer models.
\end{abstract}

\section{Introduction}

Young people working at railways officially held up the banner of volunteer services in 1993 for the first time, along with which the Center of Youth League took the lead to carry out youth voluntary actions nationwide. After 20 years of exploration and practice, the concept of voluntary services has been widely spread, the team of volunteers stronger, the projects of their services added and the mechanism of voluntary services further improved. Hundreds of millions of people have participated in voluntary services, among which many volunteer models are created such as Xu Benyu, winner of the Annual People Who Moved China and a volunteer of Western China Education Supporters; Dong Ming, Nationwide Moral Model, a volunteer confined in the chair, winner of the China Youth May $4^{\text {th }}$ Medal; Lang Kun, a volunteer who has been committed to helping the children of migrant workers for 7 years, etc. These volunteer models have brought about wide social effect, enhanced social harmony and promoted our civilization. Volunteers will be quickly forgotten by people, which proves the historical logic of quick appearance and quick disappearance if we don't do further research on values setting up volunteer models and its realization approach. It is disadvantageous to carry out voluntary services. It is rare to find a microscopic research on the value realization of individuals although many academics have done many researches of volunteers from macro perspective. In this paper, the values and approach to setting up volunteer models have been thought and studied from the perspective of social cognition and hopes to provide some references and advice to the management of setting up volunteer models.

\section{Cognition of volunteer models in social groups}

Volunteer models are excellent practitioners of voluntary spirits and faithful transmitters of voluntary concept. Volunteer models are not only members of volunteer groups but they also made outstanding contributions in voluntary fields. They are those volunteers who are influential and representative and are widely recognized and accepted by the society. Some relevant questionnaire surveys were carried out to get straight the social cognition and recognition of volunteer models. The method of nonrandom selection was adopted in the questionnaire survey. Questionnaires were randomly distributed to such areas as Longli, Daozhen and Songtao of Guzhou province, Wuhan and Dangyang of Hubei province. Investigation Methods consist of network questionnaires and posted questionnaires. This survey covered both urban and rural areas, students and social persons. 160 pieces of questionnaires were distributed, 154 of which were retrieved. The effective rate is $96.25 \%$. In addition, interviews with some of the volunteers were done to remedy the shortcomings of questionnaires. Finally, SPSS17.0 was used to analyze the data, especially the relevancy of different 
variables and the cognition of interviewees so as to gain the social cognition of "volunteer models". The attempt to analyze the relevancy between the social cognition of volunteer models and their conducts has been done. This can provide references to the digging of volunteer models and long-term efficiency mechanism.

\subsection{Cognition of volunteer models in college students.}

In the cognition investigation of social functions of volunteer models, it is indicated that $70 \%$ of college students who were interviewed acknowledged that volunteer models contributed to enhancing the influence of voluntary services, inspiring more people to participate in voluntary activities and the most important, advocating social civilization and carrying forward social righteousness. The idea that volunteer models contribute to the wider spread of volunteers and voluntary activities holds the first place. The idea that more people will be inspired to participate in voluntary activities which will create a good atmosphere of mutual help holds the second place. The idea that volunteer models contribute to advocating social civilization and carrying forward social righteousness holds the third place. The idea that volunteer models have no social influence holds the fourth place. Therefore, to some extent, volunteer models have their values in inspiring and mobilizing social members to participate in voluntary services. Meanwhile, setting up volunteer models can help college students objectively get to know relevant voluntary activities and realize the significance of voluntary services with a more visual perspective so that they will take a more active attitude in voluntary services.

\subsection{Cognition of volunteer models in social personnel.}

The investigation indicated that most people knew or participated in voluntary services of some kind, including thematic public benefit activities such as supporting poverty-stricken people, giving literacy education to the disabled, preventing AIDS and environmental protection and energy saving, etc. and they also knew such voluntary services as bringing science and technology to the countryside, safeguarding legal rights and lending legal assistance, nursing home services, assistance of troubled youngsters, supporting education, medical treatment and public health services and international aid, etc. ${ }^{[1]}$, among which college students' supporting boarder areas and supporting education is the most they knew.

The investigation indicated that there is correlativity between the two variables, the level of education and the experiences of voluntary services $(E=0.313 \mathrm{E} 2=0.098)$, the relation between saliency and correlativity is also obvious $(0.029<0.05)$. This means the better educated people are, the more willing they are to participate in voluntary services. Many of them acknowledged that their experiences of voluntary service were in college time, getting the information mainly from Youth League Committee and Youth Volunteer Association of universities. The investigation results show the correlation index $\mathrm{R}=-0.016$ between age and their experiences of voluntary services, which means that these two variables share negative correlation while having certain relevancy. This also means that the younger they are, the stronger their willingness to participate in voluntary services is. This result accords with the reality of volunteers in our country. At present, the major groups of volunteers in China are young volunteers. Developing youth volunteers is the major work of promoting voluntary services.

\section{Values and significance of setting up volunteer models}

With the development of voluntary activities, some people who have made outstanding contributions and their stories gain recognition from both their universities and all sectors of society. The width and breadth of their influence has been enlarged. Such people or stories are volunteer (voluntary services) models. Yet, many people show their doubts when they see increasing numbers of volunteer models (voluntary services) and the wide publicity of them by media. The major doubts include "Whether voluntary services will decay by means of publicizing stars? ", "Whether the motives of other volunteers who participated in voluntary services will be influenced in a bad manner?”, etc.. It is discovered that volunteers all went through a series of psychological adjustments which includes a heart of gratitude, a heart of contributing to the society and a heart of adjusting their 
attitudes when facing doubts. Participants in voluntary services also gain the chance of self-reflection and moral improvement through moral practices, which is beneficial to the perfection of their own morality. Judging from the facts that volunteer models can influence not only themselves but also the society (mainly college students), we conclude that the positive significance of setting volunteer models (voluntary stories) far outweigh their negative significance.

\subsection{Seeing from the aspect of volunteers (voluntary services)}

It is a means for individual volunteer to realize self-value through setting up volunteer models. Individual value is reflected through social value and self-value. Volunteer models realize social values through making contributions to the society by their own efforts and giving; they realize self-values when the society recognize and affirm their contributions; volunteers gain self-improvement through it. After being set up as volunteer models, social focus on their conducts will increase. Therefore, they have to elevate their qualities so as to exert their influence. This will urge volunteer models to explore new ways and methods in voluntary services. They will have to exploit new fields of voluntary services and improve levels and capability of voluntary services that can match their own images as volunteer models. Meanwhile, it promotes the development of voluntary services.

\subsection{Seeing from the aspect of society (mainly college students)}

First, volunteer models can set good examples for others and introduce more college students into voluntary services. Volunteer models are publicized through posters, advertising videos and news reports, etc. to enable college students to know relevant contents of voluntary services in a thorough way. They have certain impact on college students and encourage them to join in the volunteer groups and experience in person the benefits voluntary activities bring to them. Second, it will decrease the obstruction college students may meet with in voluntary activities. Generally speaking, the activities that volunteer models participated in were mature and full of social significance. Shaping these activities into models will help college students "imitate" in the course of voluntary services, which will avoid aimless and directionless voluntary behaviors and, to a greater extent, improve the quality and efficiency of voluntary services. At the same time, some unconscious innovation will come along in the course of "imitating” related voluntary services and thus boost th

\section{Exploration and analysis of approaches to setting up volunteer models}

Fields of voluntary services are further exploited, objects of voluntary services are expanded and contents of voluntary services are enriched with the knowledge of voluntary activities throughout the country. Meanwhile, the level of conformity between voluntary services and social demands has increased. Social personnel have comparatively comprehensive and objective knowledge of volunteers, volunteers gained relatively high social recognition and mutual interaction between volunteers and the society has been realized. When an ordinary volunteer has been dug out and publicized by media, he/she will grow into a volunteer model. Yet the prerequisite is that he/she can find the social soil necessary for his/her growth. In combination with relevant investigation results and interviews, we conclude the following means to set up volunteer models:

\subsection{Strengthening social mobilization of voluntary services}

It is indicated that the better people are educated, the more willing they are to participate in voluntary services and the higher knowledge and recognition they have for the values and ideas of voluntary services. Therefore, we should publicize spirits of voluntary services and popularize the concept of social services by means of publicizing all kinds of voluntary cultural activities through media and in combination with Chinese traditional culture. We should try to make the spirits and concept of volunteers to be more widely cognized, accepted and acknowledged among the masses so that a positive atmosphere can be created nationwide. We should lift the social status of volunteers through all kinds of public opinions by publicizing the significance of voluntary activities ${ }^{[4]}$. For this we should provide feasible approaches and methods to inspire civil participants' enthusiasm and encourage people from all walks of life and of all age groups to devote to voluntary activities. This will solve the confusion of some senior citizens who want to contribute and find their sense of 
belonging but failed to do so. This kind of role expectation which is invisible but with extremely wide coverage will certainly exert positive influence on the springing up of volunteer models.

\subsection{Establishing management mechanism of voluntary services}

Observing volunteers in the 2008 Beijing Olympic Games, the voluntary earthquake relief work in the 5.12 Wenchuan Earthquake and volunteers in 2010 Shanghai World Expo and communicating with some of the volunteers, we found that large numbers of volunteers "flowed away", completely vanished after events and activities though large numbers of volunteers were recruited every year or at emergencies ${ }^{[5]}{ }^{[6]}$. The phenomenon of "quick recruitment, quick flow-away" exists in many volunteer organizations and non-government organizations, which obviously hinders the growth of volunteer models. The reason is that the role of volunteers is unstable. Volunteers can't perceive the importance of their voluntary roles and therefore had low expectation. Under such circumstances, they will give up this role because of either the outside impact or their subjunctive reasons. So, it is advisable to solve this problem by improving the social identity of volunteers, that is, strengthening the publicizing of volunteer models and enhancing the prominence and importance of voluntary roles so as to lay a solid mass foundation on which a long-term mechanism of volunteers management can be built.

\subsection{Intensifying the incentive mechanism of voluntary services}

Voluntary services are voluntary, non-payment and altruistic social activities. Volunteers don't pursue financial benefits. This doesn't mean that volunteers expect nothing. The expectation of volunteers is mainly reflected in spiritual pursuit. Volunteers want to gain self-worth and psychological gratification through voluntary services. Volunteers' sense of achievement, sense of belonging and sense of happiness can only be realized by volunteer organizations' adequate acceptance and affirmation of their voluntary actions. Meanwhile, basic rights and interests of volunteers should be guaranteed during the course of doing voluntary services. Currently, the complaints from volunteers (at present or in the past) concentrate mainly on the problems of incentive and guarantee. Therefore, volunteer organizations must intensify the establishment of incentive mechanism when they design and carry out voluntary activities. It is advisable to integrate demands for public welfare, professional skills of volunteers and self-development of volunteers together to realize both their social values and self-values.

\subsection{Innovating the project-carrier of voluntary services}

In the present situation of voluntary services, most volunteers participated in ordinary voluntary services which are simple assisting work and require low technology. Volunteers of higher income participated in voluntary services by means of donating money or materials. Volunteers of lower income participated in voluntary services by means of contributing time and energy. Other groups,( such as immigrant workers, retirees and self-employers) find no way to participate in voluntary services though they have high enthusiasm. These solidified voluntary service patterns and project carriers go against the cultivation and development of volunteer models. Volunteer organizations should create more open and equal atmosphere in voluntary services to enable volunteers to transform from "participants" into active "managers" who can improve voluntary activities. Besides, new ideas will generate during the collision between their own professional fields. They can further innovate voluntary service projects and carriers and create more possibilities for the cultivation and setting of volunteer models.

The present and near future periods are the critical periods for our country to build a well-off society in an all-round way, and a hard period to deepen opening-up and reform and speed up and transform economic development means. There is wide demand for public services and people have endless desires for moral models. A big group of volunteer models are needed to maintain the further development of voluntary services. We should establish long-term mechanism through combining Leifeng spirits and voluntary services. We should produce growing soil for volunteer models and ideal patterns through daily, endurable, professional and projectized voluntary activities. Let volunteer models become a phenomenon around us and a fashion as well. 


\section{References}

[1] Fan Jin. Research on Volunteer Role Identity. Degree dissertation of postgraduate from Shanghai Academy of Social Sciences, 2006 (3).

[2] Wang Xuanqing: Calm Thinking of Social Voluntary Services, community, 2004

[3] Jin Jing: Research on the situation of development and function of China Volunteer Organizations, Shanghai Normal University, 2007

[4] Gao Yang: International NGO: Different Origins, Varied Natures and Tendency of Globalization, Website of China Development Bulletin: www.chinadevelopmentbrief.com.

[5]Referred to:Website of China Volunteers[EB/OL].http://www.zgzyz.org.cn/volunteer/index.html.

[6] Referred to: Li Tuqiang. Volunteers and Voluntary Spirits: Important Inner Drive of Harmonious Society 